\title{
Characterization of the size and location of dyssynchronous regions in patients undergoing CRT
}

\author{
Jonathan Suever ${ }^{1 *}$, Brandon K Fornwalt ${ }^{2}$, Michael Lloyd ${ }^{3}$, John N Oshinski ${ }^{1,4}$ \\ From 15th Annual SCMR Scientific Sessions \\ Orlando, FL, USA. 2-5 February 2012
}

\section{Background}

The amount and location of left ventricular (LV) mechanical dyssynchrony affects an individual's ability to respond positively to cardiac resynchronization therapy (CRT) [Bax et al JACC 2005]. By using high temporal resolution short-axis cines, it is possible to derive radial motion curves throughout the LV. These radial motion curves can be used to create maps showing dyssynchronous regions in patients enrolled for CRT.

The objective of this study was to characterize the size and location of areas of mechanical dyssynchrony in patients scheduled for CRT by comparing their radial wall motion curves to radial motion curves from normal subjects.

\section{Methods}

CMR was performed in 5 normal subjects with no presence of dyssynchrony (QRS $<120 \mathrm{~ms})$ and 13 patients scheduled for CRT that met current inclusion criteria (QRS $>120 \mathrm{~ms}$, NYHA HF class III-IV).

Endocardial borders were traced in normal subjects and patients on high-temporal resolution SSFP shortaxis cines (60 frames per cardiac cycle). Radial shortening at 100 locations around the contour relative to the center of mass of the LV was determined for each slice. A reference curve was generated for each patient by averaging all curves with a similar trajectory using quality threshold (QT) clustering. The temporal delay between the radial motion curves at each location relative to the reference was determined using cross-correlation analysis. By repeating this analysis at all locations throughout the LV, a mechanical dyssynchrony map was generated and projected onto an AHA 17-segment bullseye.

The mean and standard deviation of delay times throughout the LV were determined in the normal subjects. A "normal file" was defined using a $95 \%$ confidence interval based on these subjects. By comparing patients to this normal file, we could identify 1) the most dyssynchronous region and 2) the size of this dyssynchronous region.

\section{Results}

In the normal subjects, the normal range of delay times was -49 to $47 \mathrm{~ms}$.

The most dyssynchronous region was posterolateral in 6 patients, anterolateral in 4 patients, and septal in 4 patients. The CRT patients had an average of 8.6 \pm 1.9 dyssynchronous segments which comprised 48.9 $\pm 12.1 \%$ of the LV, figure 1 .

\section{Conclusions}

Using cross-correlation analysis of radial displacement curves from high temporal resolution cine CMR images, regional mechanical dyssynchrony maps can be generated. By comparing patients to a "normal file", the size and location of dyssynchronous regions in the LV can be determined. These maps could be used for CRT LV lead placement planning.

\section{Funding}

This research was funded by the National Science Foundation Graduate Research Fellowship and the American Heart Association. 


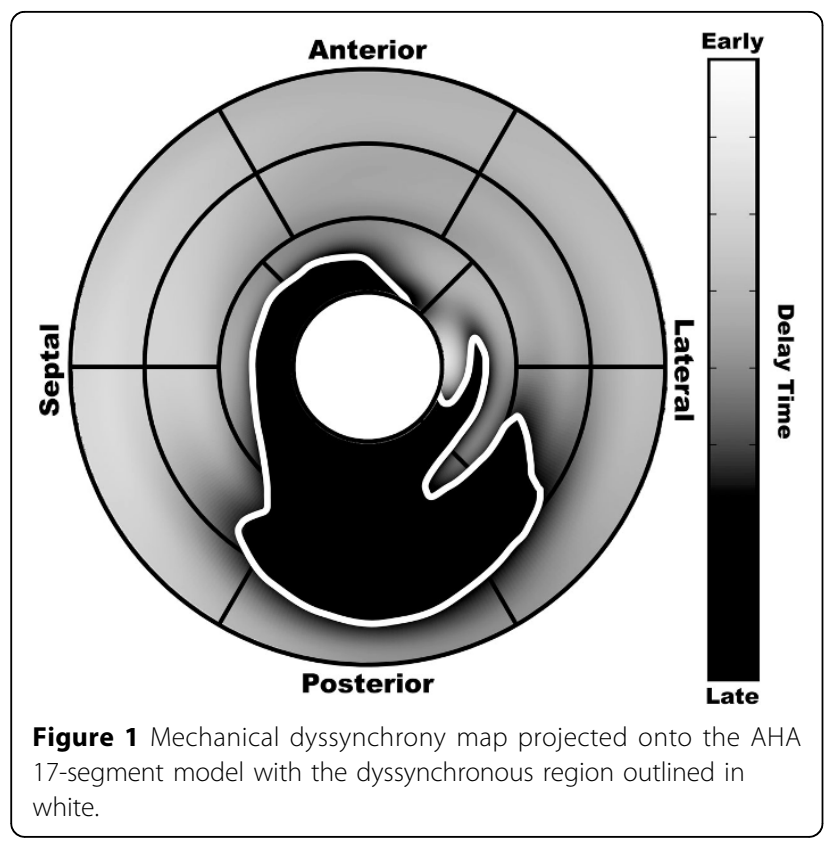

\section{Author details}

${ }^{1}$ Wallace H. Coulter Department of Biomedical Engineering, Georgia Institute of Technology / Emory University, Atlanta, GA, USA. ${ }^{2}$ Dept of Pediatrics and Biomedical Engineering, Division of Pediatric Cardiology, University of

Kentucky, Lexington, KY, USA. ${ }^{3}$ Dept of Cardiology, Division of

Electrophysiology, Emory University, Atlanta, GA, USA. ${ }^{4}$ Dept of Radiology \& Imaging Sciences, Emory University, Atlanta, GA, USA

Published: 1 February 2012

doi:10.1186/1532-429X-14-S1-P215

Cite this article as: Suever et al:: Characterization of the size and

location of dyssynchronous regions in patients undergoing CRT. Journal

of Cardiovascular Magnetic Resonance 2012 14(Suppl 1):P215.
Submit your next manuscript to BioMed Central and take full advantage of:

- Convenient online submission

- Thorough peer review

- No space constraints or color figure charges

- Immediate publication on acceptance

- Inclusion in PubMed, CAS, Scopus and Google Scholar

- Research which is freely available for redistribution

Submit your manuscript at www.biomedcentral.com/submit 